\title{
Antibacterial Activity of pH-Dependent Biosynthesized Silver Nanoparticles against Clinical Pathogen
}

\author{
Kethirabalan Chitra and Gurusamy Annadurai \\ Environmental Nanotechnology Division, Sri Paramakalyani Centre for Environmental Sciences, Manonmaniam \\ Sundaranar University, Alwarkurichi, Tamilnadu 627412, India
}

Correspondence should be addressed to Gurusamy Annadurai; gannadurai@hotmail.com

Received 17 February 2014; Revised 26 April 2014; Accepted 5 May 2014; Published 21 May 2014

Academic Editor: Beom Soo Kim

Copyright (C) 2014 K. Chitra and G. Annadurai. This is an open access article distributed under the Creative Commons Attribution License, which permits unrestricted use, distribution, and reproduction in any medium, provided the original work is properly cited.

\begin{abstract}
Simple, nontoxic, environmental friendly method is employed for the production of silver nanoparticles. In this study the synthesized nanoparticles UV absorption band occurred at $400 \mathrm{~nm}$ because of the surface Plasmon resonance of silver nanoparticles. The $\mathrm{pH}$ of the medium plays important role in the synthesis of control shaped and sized nanoparticles. The colour intensity of the aqueous solution varied with $\mathrm{pH}$. In this study, at $\mathrm{pH} 9$, the colour of the aqueous solution was dark brown, whereas in $\mathrm{pH} 5$ the colour was yellowish brown; the colour difference in the aqueous solution occurred due to the higher production of silver nanoparticles. The antibacterial activity of biosynthesized silver nanoparticles was carried out against $E$. coli. The silver nanoparticles synthesized at $\mathrm{pH} 9$ showed maximum antibacterial activity at $50 \mu \mathrm{L}$.
\end{abstract}

\section{Introduction}

Nanoscience and nanotechnology is an emerging field, which involves in the synthesis, application of nanoscale materials, and structures usually in the range of 1 to $100 \mathrm{~nm}$ [1]. Due to the optical, electronic, magnetic, and chemical properties and their possible applications in subsequent technology development, nanoparticles synthesis has received considerable attention in recent years [2]. Metal nanoparticles are having considerable interest in the fast-developing area of nanotechnology because of its applications [3]. Currently various types of metal inorganic nanoparticles zinc, titanium, magnesium, copper, gold, alginate, and silver have been synthesized using various techniques [4].

Biological synthesis of nanoparticles is an alternative method of chemical and physical methods; various organisms are used for nanoparticles synthesis, because of its effectiveness and flexible biological factors $[5,6]$. A major aim of research in nanotechnology is a synthesis of greener nanomaterials and the development of swift and steadfast experimental protocols for the synthesis of green nanomaterials includes a range of size, chemical compositions, high monodispersity and large scale production which are the key features of nanotechnology [7]. There is a great need to develop clean, nontoxic chemicals and environmentally benign solvents and renewable materials mediated synthesis method; thus a biological mediated synthesis of nanoparticles has received significant consideration in the last decade [8]. Both unicellular and multicellular organisms produce inorganic materials by intracellular or extracellular method. Magnetotactic bacteria, diatoms, and S-layer bacteria are good examples of microorganisms producing inorganic materials [9].

Metallic nanoparticles have been used in biosensing, media recording, optics, catalysis, and environmental remediation [10]. Traditionally silver has been used in customary medicine to gastronomic items because of their disinfecting effect [11]. Because of their unique optoelectronic and physicochemical properties, silver nanoparticles have attracted remarkable attention. Due to their distinctive properties such as good electrical conductivity, chemical stability, and catalytic and antibacterial activities, the silver nanoparticles are gaining more interest and most widely used [12]. The noxious nature of silver nanoparticles against various microorganisms 
has been well known; because of their antibacterial properties, silver nanoparticles are being used in the formulation of dental resin composites and ion exchange fibers and in coatings for medical devices $[13,14]$.

In this study, the silver nanoparticles were synthesized by an extracellular synthesis process using Bacillus brevis cell culture and then the effect of $\mathrm{pH}$ on the synthesis of silver nanoparticles was examined by changing the $\mathrm{pH}$ of the aqueous cell filtrate with $0.1 \mathrm{~N}$ sodium hydroxide and hydrochloric acid. The synthesized nanoparticles were characterized; the antibacterial activity of silver nanoparticles was examined against E. coli.

\section{Experimental}

2.1. Materials. Silver nitrate, Nutrient agar, Nutrient broth, Luria Bertani medium, Sodium chloride, and Hydrochloric acid were obtained from Himedia Pvt. Ltd., India. E. coli was purchased from Microlab, Arcot, Tamilnadu. The bacteria were isolated from pond water and identified as Bacillus brevis using Bergey's manual.

2.2. Extracellular Synthesis of Silver Nanoparticles. The fresh Bacillus brevis culture was inoculated in nutrient broth and the flask was incubated in orbital shaker at room temperature for $24 \mathrm{hrs}$. After $24 \mathrm{hrs}$ the culture was centrifuged at $10,000 \mathrm{rpm}$ for 10 minutes, and then the obtained supernatant was collected in a conical flask. $1 \mathrm{mM}$ of silver nitrate was added to the culture supernatant to the synthesis of the silver nanoparticles, and then the flask was incubated at room temperature in orbital shaker for $48 \mathrm{hrs}$. The UV absorption spectrophotometer reading was taken at different time intervals to monitor the synthesis of silver nanoparticles extracellularly.

2.3. Effect of $p H$ on the Extracellular Synthesis of Silver Nanoparticles. The influences of $\mathrm{pH}$ on the extracellular synthesis of silver nanoparticles were carried out by changing the $\mathrm{pH}$ of the bacterial extracellular aqueous media. The different $\mathrm{pH}$ was taken (5 and 9) to examine the effect of $\mathrm{pH}$ on the synthesis of silver nanoparticles using Bacillus. The $\mathrm{pH}$ of the extracellular aqueous media was changed using $0.1 \mathrm{~N}$ Hydrochloric acid and $0.1 \mathrm{~N}$ Sodium hydroxide. UVspectrophotometer was used to take the absorption at $24 \mathrm{hrs}$ of incubation.

\subsection{Characterization of Biosynthesized Silver Nanoparticles.} The silver nanoparticles were synthesized using the abovementioned process and then the air dried sample was used to characterization technique. The UV (Perkin Elmer) absorbance spectra were taken at various time intervals at different wavelength. Powder X-ray diffractometer (Bruker D8 Advance uses $\mathrm{CuK} \alpha$ radiation, at the $40 \mathrm{kev}$ in the range of 10-80) was used to analyze the nature of the nanoparticles. Scanning electron microscope was used to identify the morphology of the synthesized silver nanoparticles. EDAX was used to show the element of the nanoparticles. The functional groups of biologically synthesized dried nanoparticles were observed using Fourier Transform Infrared Spectrometer (Thermo Nicolet Model: 6700). The sample mixed with $\mathrm{KBr}$ and then pressed into thin pellet. Infrared spectra were measured at the wavelength in the range of $400-4000 \mathrm{~cm}^{-1}$.

2.5. Antibacterial Activity of Silver Nanoparticles. The antibacterial activity of biosynthesized silver nanoparticles was carried out against Escherichia coli. Various concen-trations $(10 \mu \mathrm{L}, 20 \mu \mathrm{L}, 30 \mu \mathrm{L}, 40 \mu \mathrm{L}$, and $50 \mu \mathrm{L})$ of silver nanoparticles (synthesized using different $\mathrm{pH}$ (5 and 9) and original $\mathrm{pH}$ (7.2)) were used for examining the antibacterial activity of silver nanoparticles. The well-diffusion method was used to determine the antibacterial activity of silver nanoparticles; the well was formed in the medium using needle; then the colloidal silver nanoparticles were pipette out into the wells, and then the plates were incubated at $37^{\circ} \mathrm{C}$ for $24 \mathrm{hrs}$. After $24 \mathrm{hrs}$ of incubation, the plates were observed for the zone of inhibition.

\section{Results and Discussion}

Several physical and chemical methods have been used for the synthesis of metallic nanoparticles; however, there is a need to develop simple and ecofriendly method to synthesis the metallic nanoparticles [15]. As a result of the growing success and simple process for the nanoparticles formation, the biological organisms in this field are swiftly gaining importance [16]. Silver nanoparticles have attractive physicochemical properties; therefore, silver nanoparticles play a profound role in the area of biology and medicine [17]. In the present study, an ecological cost effective method is employed for the extracellular synthesis of silver nanoparticles using Bacillus brevis cell filtrate.

The preliminary confirmation for the formation of silver nanoparticles was the visual observation of colour change of the aqueous solution of bacterial culture. Before (a) the addition of silver nitrate the culture was in yellow colour and after (b) addition of silver nitrate, the extracellular culture colour was changed to white precipitate and at $24 \mathrm{hrs}$ (c) of reaction, the colour of the solution was changed to brown (Figure 1 inset). Kalimuthu et al. [18] synthesized silver nanocrystals using Bacillus licheniformis; they obtained the similar colour changes during the formation of silver nanoparticles. The UV absorption spectral studies were carried out to confirm the formation of silver nanoparticles using Bacillus brevis. Figure 1 shows UV absorption spectrum; the peak is found at $400 \mathrm{~nm}$ and the maximum absorption peak occurred at 24 hrs. Because of the excitation of surface Plasmon resonance, the colour change occurred after the addition of silver nitrate in the extracellular aqueous medium; it indicates the formation of silver nanoparticles [12]. Prakash et al. [19] synthesized silver nanoparticles using Bacillus megaterium; they obtained the maximum absorption peak at $435 \mathrm{~nm}$ and they stated the band occurred due to the surface Plasmon resonance of silver nanoparticles. Figure 2 shows the effect of $\mathrm{pH}$ on the synthesis of silver nanoparticles. At $\mathrm{pH}$, the maximum production of silver nanoparticles occurred. The absorption peak occurred at $420 \mathrm{~nm}$ and $460 \mathrm{~nm}$ for 


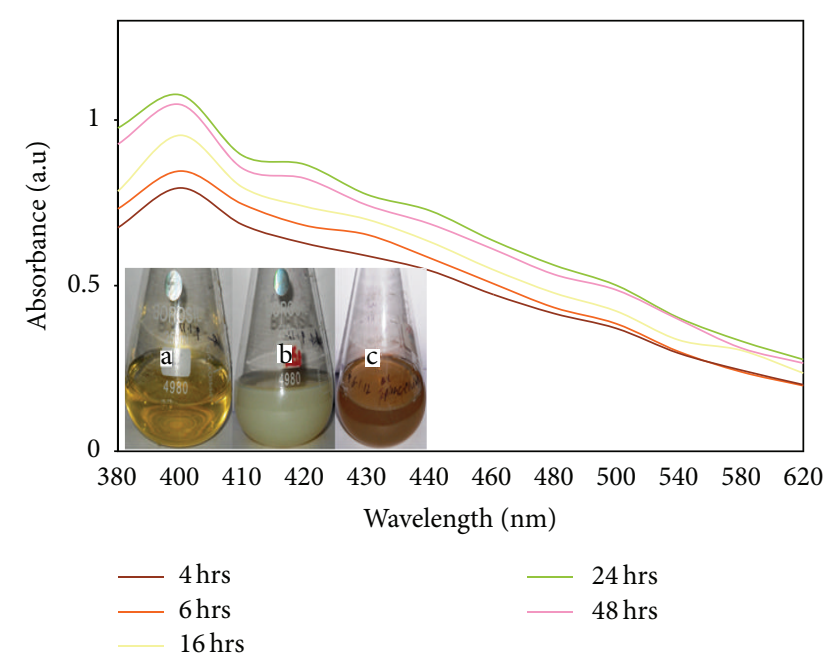

FIGURE 1: UV-spectrophotometer absorption of silver nanoparticles synthesized using Bacillus brevis, inset (a) bacterial culture before the addition of silver nitrate, (b) after addition of silver nitrate, and (c) after $24 \mathrm{hrs}$ of reaction.

pH 9 and $\mathrm{pH} \mathrm{5,} \mathrm{respectively.} \mathrm{The} \mathrm{inset} \mathrm{of} \mathrm{Figure} 2$ shows the colour variation of the medium; it indicated that higher amount of silver nanoparticles formation occurred at $\mathrm{pH} 9$. Nayak et al. [20] stated that the band at $420 \mathrm{~nm}$ indicated the spherical shape of nanoparticles, whereas at $480 \mathrm{~nm}$ the particles are different shapes. Figure 3 shows the XRD pattern of the silver nanoparticles synthesized using Bacillus brevis. The XRD pattern indicated strong peaks in the entire spectrum of $2 \theta$ values ranging from 20 to 80 . The silver nanoparticles synthesized in this experiment were in the form of nanocrystals. In the XRD spectrum, the peaks at $2 \theta$ values of $32.24^{\circ}, 48.11^{\circ}, 58.64^{\circ}$, and $77.47^{\circ}$ analogous to (111), (200), (220), and (311) planes confirmed the face centered cubic crystalline structure of nanosilver [21]. There was an unassigned peak in the XRD spectrum, due to the presence of bioorganic phase that occurred in the surface of the silver nanoparticles [22].

Figures 4(a)-4(d) show the SEM and EDX image of the biosynthesized silver nanoparticles. In Figure 4(a) the particles agglomerated and there was no understandable shape. Figure 4(b) shows the SEM image of silver nanoparticles synthesized using $\mathrm{pH}$ 5; the synthesized particles were hexagonal in shape and the size of the nanoparticles was in the range of 60-110 nm. Figure 4(c) shows the SEM image of the silver nanoparticles synthesized using $\mathrm{pH}$ 9; the particles were spherical and the obtained particles are $10-40 \mathrm{~nm}$ in size. Figure 4(d) shows the EDX spectrum of silver nanoparticles; the strong peak at $3 \mathrm{keV}$ indicated the presence of elemental silver nanoparticles. The size of nanoparticles is high at acidic $\mathrm{pH}$, because the nucleation process for the formation of silver nanocrystal at acidic $\mathrm{pH}$ is slow; thus the low amount of large size particles formed. While at high $\mathrm{pH}$, fast nucleation process occurred because of the accessibility of -OH ions; thus high amount of small size particles formed [23].

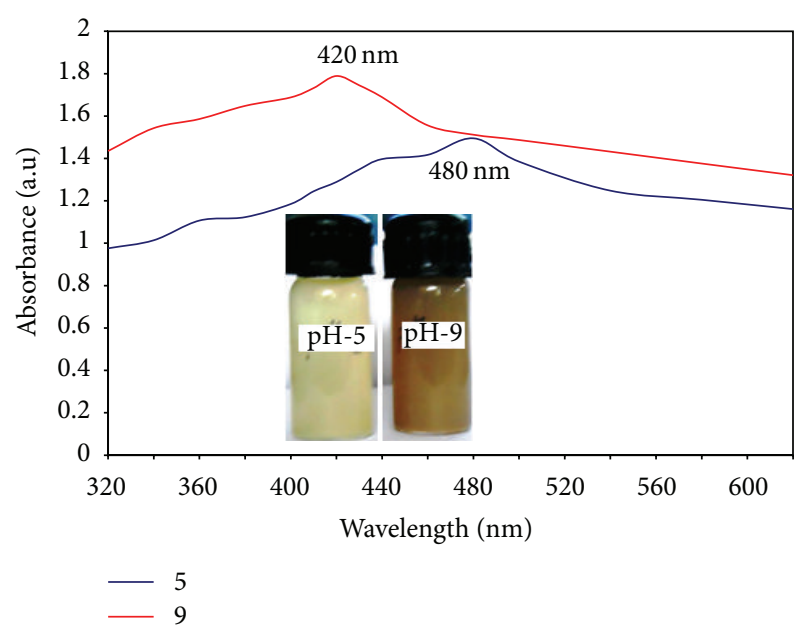

Figure 2: UV-spectrophotometer absorption of the effect of $\mathrm{pH}$ on the synthesis of silver nanoparticles. Inset shows that the colour variation at $\mathrm{pH} 5$ and the synthesis of silver nanoparticles is low and at $\mathrm{pH} 9$ the production of silver nanoparticles is high.

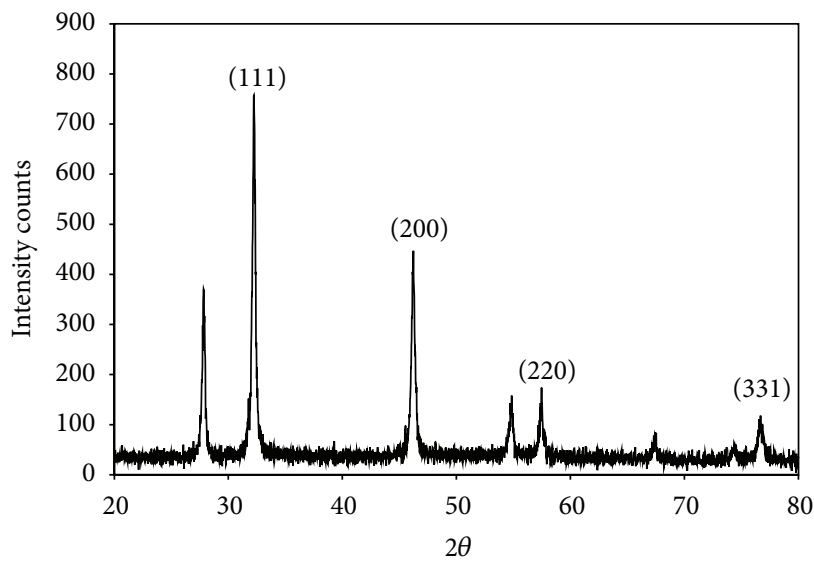

FIGURE 3: X-ray diffractometer of silver nanoparticles synthesized using Bacillus brevis.

The FTIR spectrum of silver nanoparticles was synthesized using Bacillus brevis (Figure 5). The band at $3412 \mathrm{~cm}^{-1}$ and $2918 \mathrm{~cm}^{-1}$ represents the $\mathrm{O}-\mathrm{H}, \mathrm{C}-\mathrm{C}$ stretching vibration [24]. The band at $1634 \mathrm{~cm}^{-1}$ represents the $-\mathrm{NH}$ stretching vibration of the amide group [12]. The bands at $1381 \mathrm{~cm}^{-1}$ and $1058 \mathrm{~cm}^{-1}$ represent the aromatic and aliphatic amines of C-N stretching vibrations of protein [25]. The FTIR results confirmed that the protein might be responsible for the formation of silver nanoparticles [26].

The well-diffusion method was used to provide evidence for the antibacterial activity of biosynthesized silver nanoparticles against E. coli. Figure 6 shows the antibacterial effect of silver nanoparticles (synthesized using (a) original $\mathrm{pH}$ (7.2) (b) $\mathrm{pH}-5$ and $\mathrm{pH}-(9)$ ) against E. coli. The antibacterial activity of silver nanoparticles was indicated 


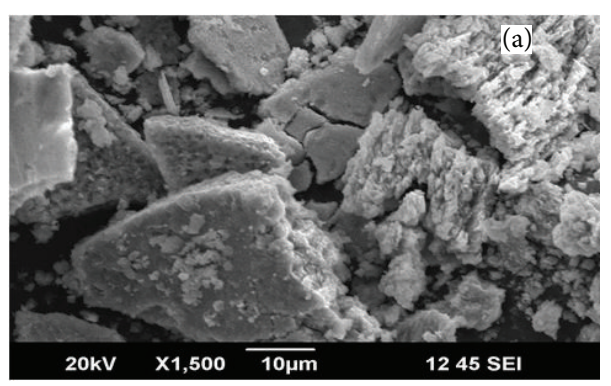

(a)

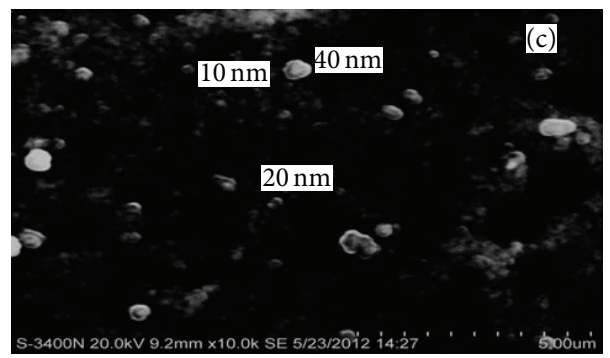

(c)

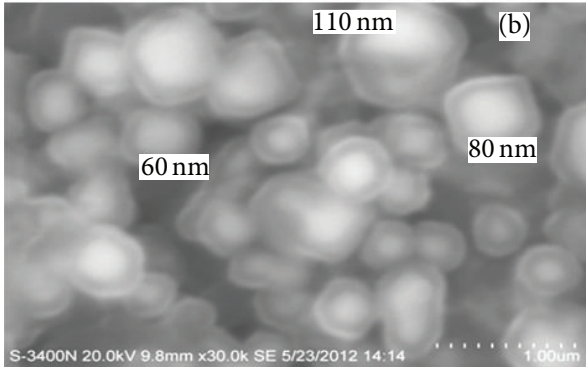

(b)

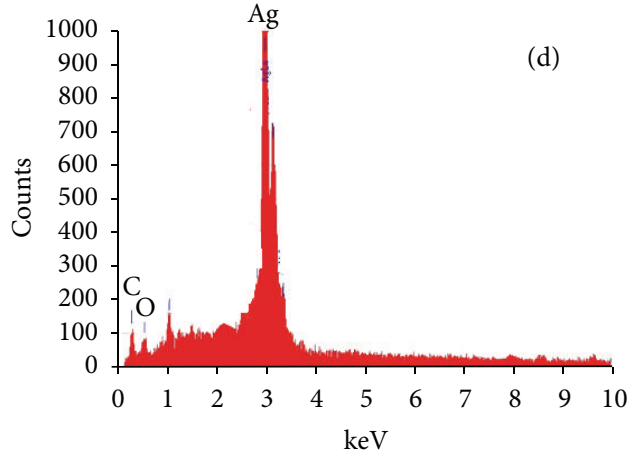

(d)

FIGURE 4: SEM image of the synthesized silver nanoparticles. (a) Original pH (7.1), (b) pH 5, (c) pH 9, (d) EDAX spectrum of silver nanoparticles.

by the formation of the zone and the zone of inhibition measured as $\mathrm{mm} /$ diameter. The maximum zone of inhibition occurred at $50 \mu \mathrm{L}$ concentration of silver nanoparticles. The silver nanoparticles synthesized using $\mathrm{pH} 9$ show higher antibacterial activity $(13 \mathrm{~mm})$ against $E$. coli. Silver has been well-known disinfectant for long years. The use of silver compounds is reduced due to some limitations; recently metallic silver in the form of silver nanoparticles shows well antibacterial activity against many microorganisms [27]. Small sized nanoparticles showed more antibacterial activity than large size particles because small sized particles affect a large surface area of the bacteria [28]. There are some possible mechanisms for the antibacterial activity of silver nanoparticles; early studies reported that the electrostatic interaction may be possible reason for the antibacterial activity of silver nanoparticles [29]. Early studies stated that the bacterial proteins are inactivated by the interaction between silver nanoparticles and thiol groups of bacterial protein. Nayak et al. [20] reported the similar results while using silver nanoparticles synthesized by different $\mathrm{pH}$; they stated that the initial $\mathrm{pH}$ of the medium, surface area, and shape plays important role in the antibacterial efficiency of silver nanoparticles.

\section{Conclusion}

The silver nanoparticles were synthesized using Bacillus brevis by extracellular method. The different sized and shaped

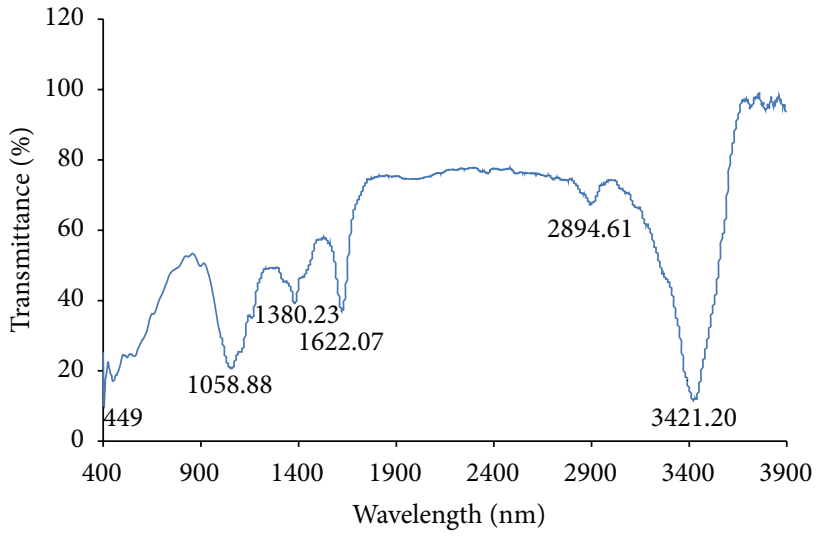

FIGURE 5: FTIR Spectrum of biosynthesized silver nanoparticles using Bacillus brevis.

nanoparticles formed while changing the $\mathrm{pH}$ of the aqueous solution. The biosynthesized silver nanoparticles were in face centered cubic crystalline structure. The proteins which are present in the bacteria may be possible reason for the synthesis of silver nanoparticles. The $\mathrm{pH}$ of the aqueous solution plays important role in the antibacterial activity of silver nanoparticles; the smallest nanoparticles synthesized using $\mathrm{pH} 9$ showed more antibacterial activity than large particles which are synthesized using original $\mathrm{pH}$ and $\mathrm{pH} 5$. 


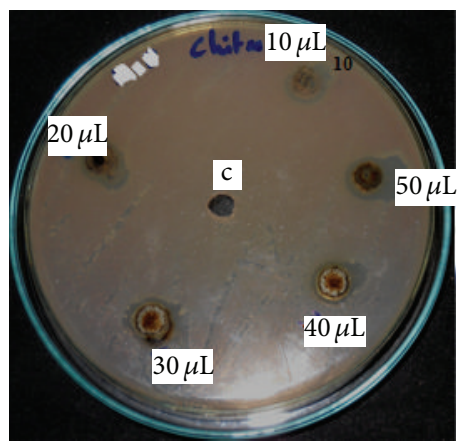

(a)

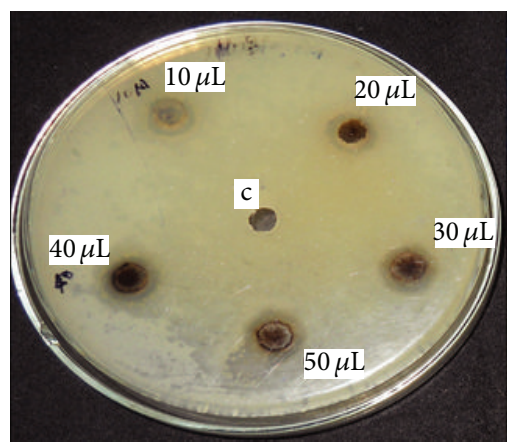

(b)

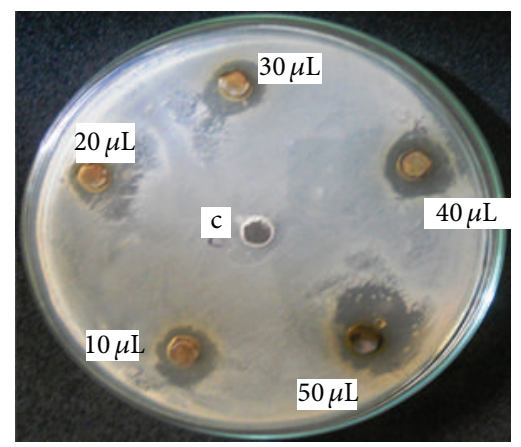

(c)

Figure 6: Antibacterial activity of silver nanoparticles. (a) Silver nanoparticles synthesized using original pH of the extracellular aqueous solution, (b) silver nanoparticles synthesized at $\mathrm{pH}$ 5, and (c) silver nanoparticles synthesized at $\mathrm{pH} 9$.

\section{Conflict of Interests}

The authors declare that there is no conflict of interests regarding the publication of this paper.

\section{Acknowledgment}

The authors gratefully acknowledge the DST-FIST sponsored programme, Department of Science Technology, New Delhi, India, for funding the research development (Ref no. S/FST/ESI-101/2010) to carry out this work.

\section{References}

[1] V. K. Sharma, R. A. Yngard, and Y. Lin, "Silver nanoparticles: green synthesis and their antimicrobial activities," Advances in Colloid and Interface Science, vol. 145, no. 1-2, pp. 83-96, 2009.

[2] M. Fu, Q. Li, D. Sun et al., "Rapid preparation process of silver nanoparticles by bioreduction and their characterizations," Chinese Journal of Chemical Engineering, vol. 14, no. 1, pp. 114117, 2006.

[3] Q. S. Wei, J. Ji, J. H. Fu, and J. C. Shen, "Norvancomycin-capped silver nanoparticles: synthesis and antibacterial activities against E.coli," Science in China, Series B: Chemistry, vol. 50, no. 3, pp. 418-424, 2007.

[4] K. S. H. Naveen, G. Kumar, L. Karthik, and K. V. B. Rao, "Extracellular biosynthesis of silver nanoparticles using the filamentous fungus penicillium sp," Archives of Applied Science Research, vol. 2, no. 6, pp. 161-167, 2010.

[5] V. P. Ghodake, P. T. Kininge, S. P. Magdum, A. S. Dive, and M. M. Pillai, "Biosynthesis of silver nanoparticles using Trichosporon beigelii NCIM 3326 and evaluation of their antibacterial activity," Journal of Engineering Research and Studies, vol. 2, no. 1, pp. 32-36, 2011.

[6] G. Nithya, N. Hema Shepangam, and S. Balaji, "Biosynthesis of silver nanoparticles and its antibacterial activity," Archives of Applied Science Research, vol. 3, no. 2, pp. 377-380, 2011.

[7] S. Sadhasivam, P. Shanmugam, and K. Yun, "Biosynthesis of silver nanoparticles by Streptomyces hygroscopicus and antimicrobial activity against medically important pathogenic microorganisms," Colloids and Surfaces B: Biointerfaces, vol. 81, no. 1, pp. 358-362, 2010.
[8] J. Kasthuri, K. Kathiravan, and N. Rajendiran, "Phyllanthinassisted biosynthesis of silver and gold nanoparticles: a novel biological approach," Journal of Nanoparticle Research, vol. 11, no. 5, pp. 1075-1085, 2009.

[9] S. S. Shankar, A. Rai, A. Ahmad, and M. Sastry, "Rapid synthesis of $\mathrm{Au}, \mathrm{Ag}$, and bimetallic Au core-Ag shell nanoparticles using Neem (Azadirachta indica) leaf broth," Journal of Colloid and Interface Science, vol. 275, no. 2, pp. 496-502, 2004.

[10] E. C. Njagi, H. Huang, L. Stafford et al., "Biosynthesis of iron and silver nanoparticles at room temperature using aqueous sorghum bran extracts," Langmuir, vol. 27, no. 1, pp. 264-271, 2011.

[11] I. Maliszewska and M. Puzio, "Extracellular biosynthesis and antimicrobial activity of silver nanoparticles," Acta Physica Polonica, vol. 116, pp. S160-S162, 2009.

[12] K. Chitra and G. Annadurai, "Bioengineered silver nanobowls using Trichoderma viride and its antibacterial activity against gram-positive and gram-negative bacteria," Journal of Nanostructure in Chemistry, vol. 3, no. 9, 2013.

[13] C. Krishnaraj, E. G. Jagan, S. Rajasekar, P. Selvakumar, P. T. Kalaichelvan, and N. Mohan, "Synthesis of silver nanoparticles using Acalypha indica leaf extracts and its antibacterial activity against water borne pathogens," Colloids and Surfaces B: Biointerfaces, vol. 76, no. 1, pp. 50-56, 2010.

[14] I. Sondi and B. Salopek-Sondi, "Silver nanoparticles as antimicrobial agent: a case study on E.coli as a model for Gramnegative bacteria," Journal of Colloid and Interface Science, vol. 275, no. 1, pp. 177-182, 2004.

[15] K. C. Bhainsa and S. F. Souza, "Extracellular biosynthesis of silver nanoparticles using the fungus Aspergillus fumigatus," Colloids and Surfaces B: Biointerfaces, vol. 47, no. 2, pp. 160-164, 2006.

[16] R. Sanghi and P. Verma, "Biomimetic synthesis and characterisation of protein capped silver nanoparticles," Bioresource Technology, vol. 100, no. 1, pp. 501-504, 2009.

[17] R. Veerasamy, T. Z. Xin, S. Gunasagaran et al., "Biosynthesis of silver nanoparticles using mangosteen leaf extract and evaluation of their antimicrobial activities," Journal of Saudi Chemical Society, vol. 15, no. 2, pp. 113-120, 2011.

[18] K. Kalimuthu, R. Sureshbabu, D. Venkataraman, M. Bilal, and S. Gurunathan, "Biosynthesis of silver nanocrystals by Bacillus licheniformis," Colloids and Surfaces B: Biointerfaces, vol. 65, no. 1, pp. 150-153, 2008. 
[19] A. Prakash, S. Sharma, N. Ahmad, A. Ghosh, and P. Sinha, "Bacteria mediated extracellular synthesis of metallic nanoparticles," International Research Journal of Biotechnology, vol. 1, no. 5, pp. 071-079, 2010.

[20] R. R. Nayak, N. Pradhan, D. Behera et al., "Green synthesis of silver nanoparticle by Penicillium purpurogenum NPMF: the process and optimization," Journal of Nanoparticle Research, vol. 13, no. 8, pp. 3129-3137, 2011.

[21] T. Maneerung, S. Tokura, and R. Rujiravanit, "Impregnation of silver nanoparticles into bacterial cellulose for antimicrobial wound dressing," Carbohydrate Polymers, vol. 72, no. 1, pp. 4351, 2008.

[22] N. Vigneshwaran, N. M. Ashtaputre, P. V. Varadarajan, R. P. Nachane, K. M. Paralikar, and R. H. Balasubramanya, "Biological synthesis of silver nanoparticles using the fungus Aspergillus flavus," Materials Letters, vol. 61, no. 6, pp. 1413-1418, 2007.

[23] V. Deepak, K. Kalishwaralal, S. R. M. Pandian, and S. Gurunathan, "An insight into the bacterial biogenesis of silver nanoparticles, industrial production and scale-up," in Metal Nanoparticles in Microbiology, M. Rai and N. Duran, Eds., pp. 17-35, Springer, Berlin, Germany, 2011.

[24] T. C. Prathna, N. Chandrasekaran, A. M. Raichur, and A. Mukherjee, "Biomimetic synthesis of silver nanoparticles by citrus limon (lemon) aqueous extract and theoretical prediction of particle size," Colloids and Surfaces B: Biointerfaces, vol. 82, no. 1, pp. 152-159, 2011.

[25] K. Vanmathi Selvi and T. Sivakumar, "Isolation and characterization of silver nanoparticles from Fusarium oxysporum," Internationl Journal of Current Microbiology and Applied Sciences, vol. 1, no. 1, pp. 56-62, 2012.

[26] D. S. Balaji, S. Basavaraja, R. Deshpande, D. B. Mahesh, B. K. Prabhakar, and A. Venkataraman, "Extracellular biosynthesis of functionalized silver nanoparticles by strains of Cladosporium cladosporioides fungus," Colloids and Surfaces B: Biointerfaces, vol. 68, no. 1, pp. 88-92, 2009.

[27] M. Rai, A. Yadav, and A. Gade, "Silver nanoparticles as a new generation of antimicrobials," Biotechnology Advances, vol. 27, no. 1, pp. 76-83, 2009.

[28] M. Vanaja and G. Annadurai, "Coleus aromaticus leaf extract mediated synthesis of silver nanoparticles and its bactericidal activity," Applied Nanoscience, vol. 3, no. 1, pp. 217-223, 2013.

[29] H. H. Lara, E. N. Garza-Trevino, L. Ixtepan-Turrent, and D. K. Singh, "Silver nanoparticles are broad-spectrum bactericidal and virucidal compounds," Journal of Nanobiotechnology, vol. 9, no. 30, pp. 2-8, 2011. 

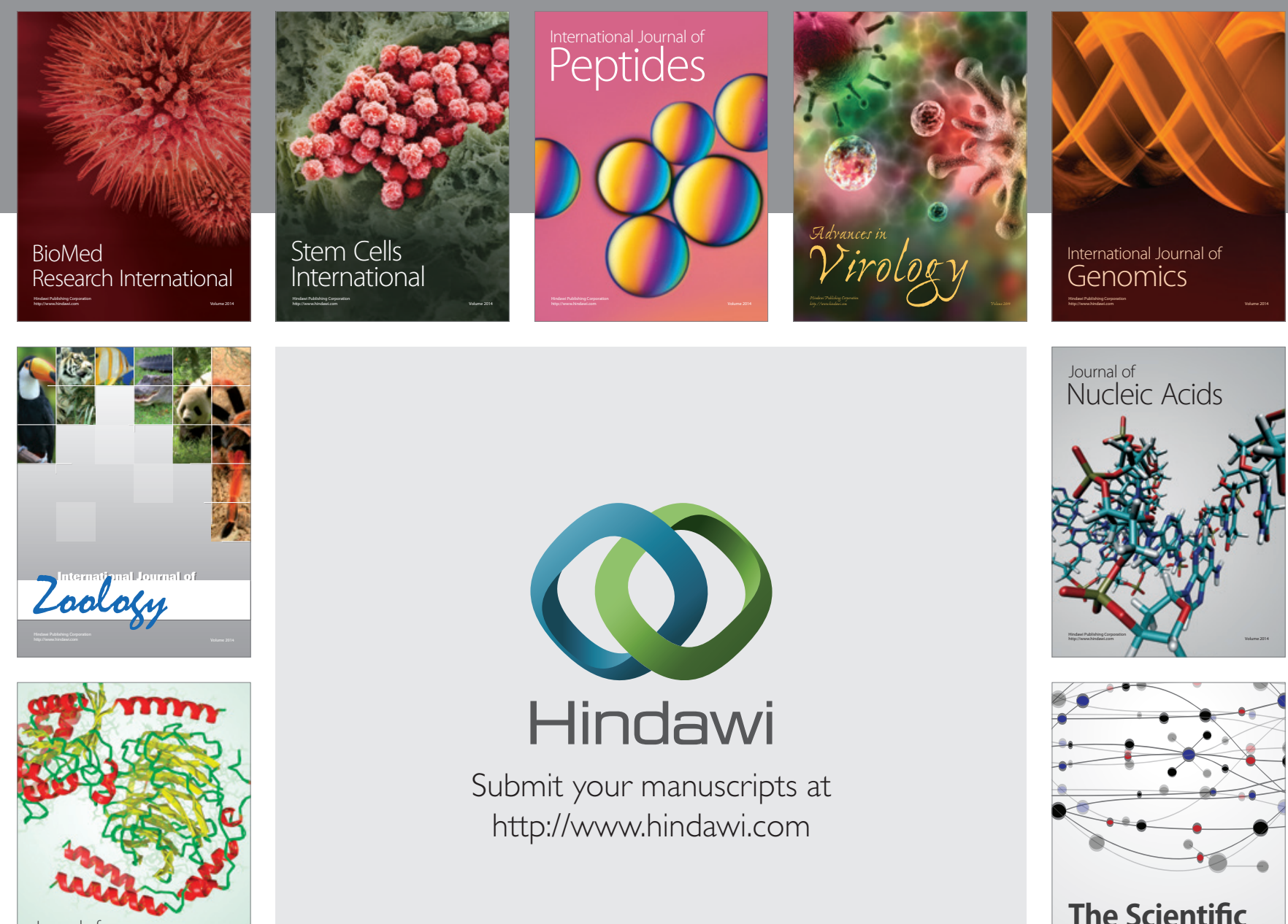

Submit your manuscripts at

http://www.hindawi.com

Journal of
Signal Transduction
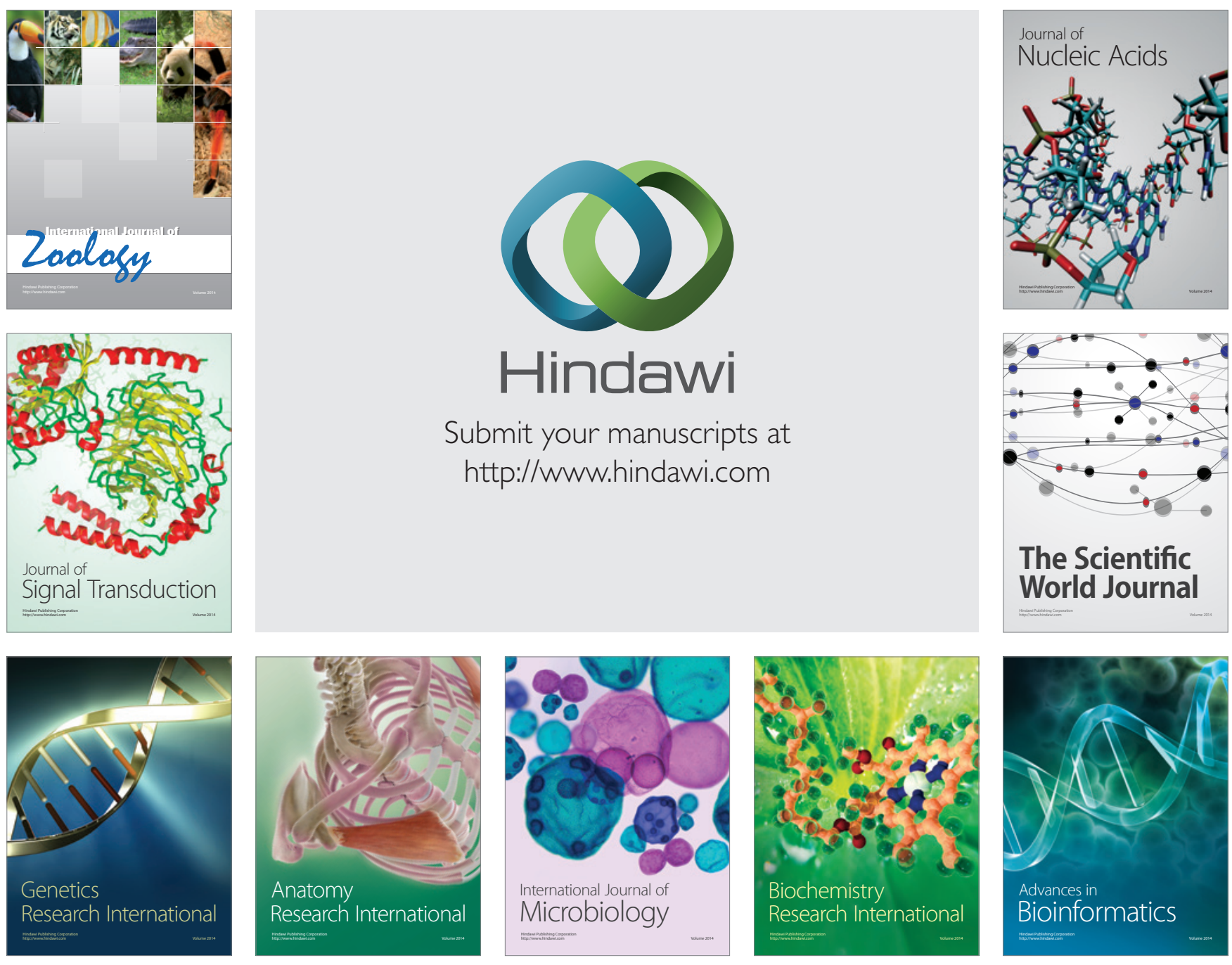

The Scientific World Journal
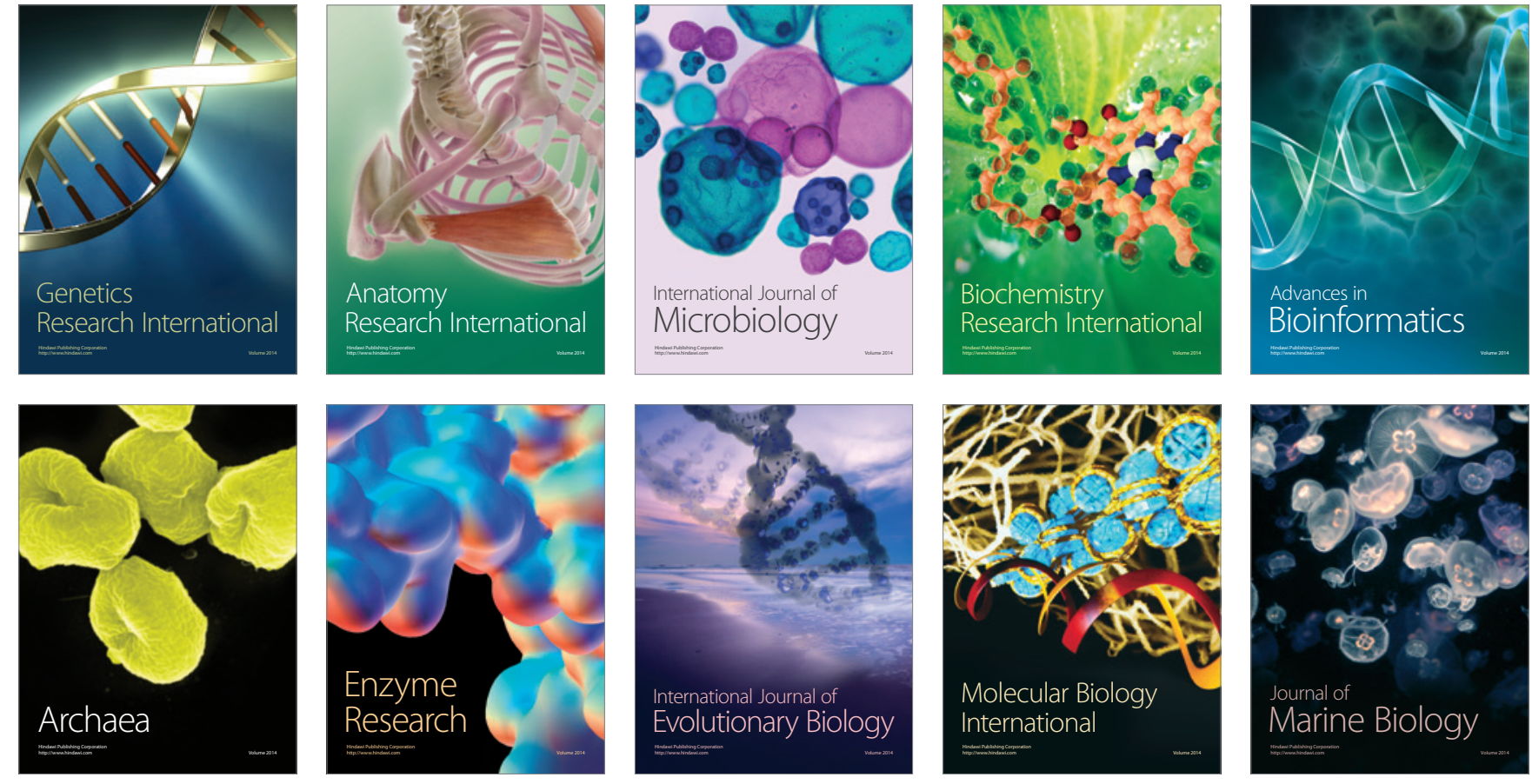